\title{
Fatores que afetam o desempenho de suínos nas fases de crescimento e terminação
}

\author{
Caio Abércio da Silva(1), Piero da Silva Agostini(2), Marco Aurélio Callegari(1), \\ Rita de Kássia Silva dos Santos ${ }^{(1)}$, Aliny Kétilim Novais ${ }^{(1)}$, Carlos Rodolfo Pierozan ${ }^{(1)}$, \\ Marcino Pereira Junior ${ }^{(1)}$, Jefferson Bastos Alves ${ }^{(1)}$ e Josep Gasa Gasó(2)
}

\begin{abstract}
(1)Universidade Estadual de Londrina, Departamento de Zootecnia, Rodovia Celso Garcia Cid, Pr 445, Km 380, Campus Universitário, CEP 86057-970 Londrina, PR, Brasil. E-mail: casilva@uel.br, marco.aurelio@vetica.com.br, rita.zoo@live.com, alinyketilim@hotmail.com, carlospierozan@hotmail.com, marcinojr@outlook.com, jefferson.vet62@gmail.com (2)Universitat Autònoma de Barcelona, Department de Ciència Animal i dels Aliments, Plaza Cívica, s/non, 08193, Bellaterra, Espanha. E-mail: pieroagostini@hotmail.com, Josep.Gasa@uab.cat
\end{abstract}

Resumo - O objetivo deste trabalho foi identificar e quantificar, por meio de modelos de regressão linear múltipla, os fatores de produção que afetam o consumo diário de ração e a conversão alimentar de suínos nas fases de crescimento e terminação, em granjas integradas a uma cooperativa. Foram avaliados os históricos produtivos de 690 lotes, que representavam aproximadamente 363 mil animais alojados entre 2010 e 2013 em 118 granjas vinculadas a uma cooperativa do Estado do Paraná. Foram considerados 44 fatores de produção relacionados a instalações, manejo, sanidade, genética e alimentação. O consumo diário de ração (CDR) foi menor nos lotes oriundos de granjas com árvores nas laterais dos galpões e naqueles formados apenas por fêmeas. Já a conversão alimentar (CA) foi melhor para os lotes provenientes de granjas com árvores nas laterais dos galpões, alojados no verão/outono, oriundos de granjas edificadas em alvenaria e que apresentavam composteira e unidades especializadas produtoras de leitões. Os pesos de entrada e de saída dos lotes influenciaram o CDR, e o peso de entrada e a duração do período de engorda, a CA. Os modelos de regressão linear múltipla possibilitam identificar variáveis de importância e estimar seus efeitos sobre a conversão alimentar e o consumo diário de ração de suínos nas fases de crescimento e terminação.

Termos para indexação: consumo diário de ração, conversão alimentar, equações, regressão múltipla.

\section{Factors affecting the performance of pigs in the growing and finishing phases}

\begin{abstract}
The objective of this work was to identify and quantify, through multiple linear regression models, the factors of production that affect the daily feed intake and feed conversion ratio of pigs in the growing and finishing phases, in farms linked to a company. The production records of 690 batches were evaluated, representing approximately 363 thousand animals housed between 2010 and 2013 in 118 commercial farms linked to a company in the state of Paraná, Brazil. Forty-four factors of production related to facilities, management, health status, genetics, and feeding were considered. Daily feed intake (DFI) was lower in batches from farms that had trees planted on the sides of the barns and in those formed only by females. The feed conversion ratio (FCR) was better in batches from farms with trees on the sides of the barns, housed during summer/fall, originated from farms with barns built of masonry and that had compost bins and specialized units for producing piglets. The initial and final weights of the batches affected DFI, and the initial weight and duration of the growing and finishing phases, the FCR. The multiple linear regression models allow identifying important variables and estimating their effects on FCR and DFI of pigs in the growing and finishing phases.
\end{abstract}

Index terms: daily feed intake, feed conversion ratio, equations, multiple regression.

\section{Introdução}

Na suinocultura, as fases de crescimento e terminação são consideradas complexas e sujeitas a muitas variáveis, com grandes transformações nos índices de desempenho (Silva et al., 2015). Fatores relacionados a manejo, nutrição, sanidade, genética e ambiência podem afetar o desempenho dos suínos do crescimento até o abate (Heck, 2009), o que torna importante, do ponto de vista econômico, reconhecê-los e possibilitar sua modificação de acordo com os interesses dos produtores, das indústrias ou das cooperativas do setor.

Os modelos matemáticos corretamente validados são ferramentas que permitem prever índices zootécnicos 
e quantificar de forma objetiva os principais fatores de produção (Silva et al., 2015). A regressão múltipla é bastante utilizada para estimar o tamanho e a significância dos efeitos de um número de variáveis independentes sobre uma variável dependente (Neale et al., 1994). Nesse tipo de análise, as variáveis preditoras podem ser contínuas, categóricas ou uma combinação das duas, e podem ser correlacionadas entre si (Hoyt et al., 2006).

Em estudos a respeito de granjas de crescimento e terminação de suínos, foram utilizados modelos de regressão para correlacionar fatores de produção com desempenho (Oliveira et al., 2009; Agostini et al., 2014; Agostini et al., 2015; Pierozan et al., 2016), principalmente em relação à carcaça (Tuovinen et al., 1992) e à sanidade (Nollet et al., 2004). Mais recentemente, em metanálise, Douglas et al. (2015) utilizaram modelos multivariados para avaliar os efeitos de fatores relacionados às características do ambiente, do animal e do alimento sobre o desempenho - (ganho de peso diário, consumo de ração e conversão alimentar) de suínos na fase de crescimento e terminação. Contudo, estes autores analisaram somente trabalhos realizados em países europeus, devido às diferenças entre continentes quanto às práticas adotadas, que incluem os ingredientes usados nas rações. Essa metanálise mostrou que o fator "país" influenciou as três variáveis de interesse analisadas, entre elas consumo de ração e conversão alimentar.

No Brasil, ainda são poucos os trabalhos que utilizam a modelagem para estabelecer correlações semelhantes sob condições de instalações, manejo e alimentação nas granjas, as quais diferem em vários aspectos dos sistemas europeus de produção. Esses trabalhos são importantes para apontar os aspectos de maior relevância que influenciam a produtividade dos animais e, consequentemente, para fornecer informações úteis que possam auxiliar em questões estruturais e de gestão das granjas. De acordo com Agostini et al. (2015), como cada empresa utiliza diferentes formas de manejo, nutrição e instalações em suas granjas, modelos desenvolvidos dentro da empresa são mais confiáveis do que os entre empresas.

O objetivo deste trabalho foi identificar e quantificar, por meio de modelos de regressão linear múltipla, os fatores de produção que afetam o consumo diário de ração e a conversão alimentar de suínos nas fases de crescimento e terminação, em granjas integradas a uma cooperativa.

\section{Material e Métodos}

Os dados sobre os lotes avaliados foram provenientes de uma base de dados e, portanto, não foi necessária a aprovação pela Comissão de Ética no Uso de Animais, uma vez que não houve uso de animais no presente trabalho. Os dados coletados corresponderam a 690 lotes de suínos em fase de crescimento e terminação (CT), o que totalizou aproximadamente 363 mil animais alojados entre 2010 e 2013 em 118 granjas comerciais $(5,85$ lotes por granja), vinculadas a um sistema cooperativo (Cooperativa Agroindustrial Consolata - Copacol) localizado no Oeste do Estado do Paraná. As granjas estavam situadas em munícipios adjacentes, limítrofes às microrregiões de Cascavel, Goioerê e Toledo, região com temperatura média anual de 20 a $23^{\circ} \mathrm{C}$, de 15 a $18^{\circ} \mathrm{C}$ no trimestre mais frio, e de 26 a $29^{\circ} \mathrm{C}$ no trimestre mais quente, com umidade relativa anual entre 70 e $80 \%$ (Caviglione, 2000). O lote foi definido como o grupo de leitões que saíram da fase de creche e foram alojados e mantidos na granja de CT até o abate. Todos os lotes foram manejados no sistema "all-in all-out".

O modelo de estudo seguiu o trabalho desenvolvido por Agostini et al. (2013). A primeira etapa consistiu na escolha das variáveis de interesse zootécnico e dos fatores de produção a serem levantados (Tabelas $1 \mathrm{e}$ 2). A escolha das variáveis levou em conta referências de trabalhos técnicos e científicos recentes, bem como a experiência da equipe proponente e dos técnicos da cooperativa. Diferentemente do trabalho de Agostini et al. (2013), foram coletados dados de todas as granjas integradas à cooperativa e foi avaliado um número maior de lotes por granja. Os dados foram referentes aos lotes alojados em diferentes estações do ano.

As variáveis avaliadas foram divididas em dependentes e independentes. No grupo das dependentes, foram analisadas as variáveis contínuas consumo diário de ração (CDR) e conversão alimentar (CA) (Tabela 1). Para cada lote, o consumo total de ração por animal foi calculado pelo total de ração fornecida ao lote durante o período em CT menos a quantidade de ração que restou nos silos quando os animais foram enviados ao abatedouro (ambos os valores em quilogramas), dividido pelo número de

Pesq. agropec. bras., Brasília, v.51, n.10, p.1780-1788, out. 2016 DOI: $10.1590 / \mathrm{S} 0100-204 \mathrm{X} 2016001000010$ 
suínos comercializados. Esse resultado foi dividido pela média de dias que os animais permaneceram na unidade de CT, o que resultou no CDR por animal. Para o cálculo da CA, o total de ração fornecida a cada lote foi dividido pela diferença do peso total dos animais enviados para abate e o peso total dos animais quando entraram na unidade de $\mathrm{CT}$; todos esses valores foram expressos em quilogramas. A taxa de mortalidade não foi considerada no cálculo do CDR e da CA, visto que o consumo de ração e o peso dos animais mortos não foram controlados pelas granjas.

Já no grupo das variáveis independentes, foram avaliadas as variáveis contínuas peso de entrada (PE), peso de saída (PS) e duração da fase de CT (DCT) (Tabela 1). O PE correspondeu ao peso vivo médio dos animais quando entraram na unidade de CT e o PS, ao peso vivo médio dos suínos no abatedouro, ambos registrados em quilogramas. A DCT foi considerada como o período, em dias, que os animais permaneceram na unidade de CT até a data em que foram encaminhados para o abate.

Foram avaliadas 44 variáveis categóricas independentes, as quais representaram os fatores de produção relacionados a instalações, manejo, alimentação, genética e estado sanitário dos rebanhos (Tabela 2).

Os dados coletados foram inseridos em uma planilha do Microsoft Excel 2007, a qual foi utilizada como base para a realização das análises estatísticas por meio do programa SAS, versão 9.2 (SAS Institute, Inc., Cary, NC, EUA). Essas análises foram realizadas em duas fases: análise exploratória e desenvolvimento do modelo, como em Maes et al. (2004), Oliveira et al. (2009) e Agostini et al. (2014).

$\mathrm{Na}$ análise exploratória, para as variáveis contínuas, foram utilizadas medidas de tendência central (média e mediana) e de dispersão (desvio-padrão, quartis e amplitude), analisadas pelo procedimento
Means do SAS (SAS Institute, Inc., Cary, NC, EUA) (Tabela 1). As distribuições das variáveis contínuas também foram avaliadas por meio do procedimento Univariate do mesmo programa. Já as variáveis categóricas foram analisadas a partir da frequência com uso do procedimento Freq, também do SAS (Tabela 2). As variáveis categóricas com ausência de variabilidade entre suas categorias, isto é, com mais de $90 \%$ do total dos lotes incluído em uma dada categoria, foram previamente rejeitadas para futuras análises estatísticas. Em todas as análises, o lote foi considerado a unidade experimental.

Posteriormente, os modelos foram ajustados a partir das variáveis que foram codificadas na primeira fase mediante regressão linear mista, tendo-se utilizado o procedimento Mixed do SAS (SAS Institute, Inc., Cary, NC, EUA). Os efeito da granja e do lote dentro da granja foram considerados como fatores aleatórios, e a variância foi estimada por meio do método de máxima verossimilhança restrita (REML). Calculou-se a variância total para CDR e CA sem (modelo nulo) e com (modelo completo) a inclusão de variáveis preditoras, e determinou-se a proporção da variância observada entre granjas e entre lotes dentro da granja. Em seguida, foram calculadas as diferenças das variâncias entre o modelo nulo e o modelo cheio referente ao $\mathrm{CDR}$ e à $\mathrm{CA}$. A comparação do ajuste dos modelos finais foi feita a partir da proporção da variância explicada pelos diferentes modelos, tendose usado o coeficiente de determinação $\left(\mathrm{R}^{2}\right)$ como parâmetro.

Um modelo de regressão simples foi utilizado, e cada variável de previsão foi incluída como um único efeito fixo para cada variável dependente. As variáveis independentes que apresentaram $\mathrm{p} \leq 0,20$ foram selecionadas para uso na análise de regressão múltipla.

As variáveis independentes no modelo multivariado foram submetidas às correlações de Pearson e

Tabela 1. Valores descritivos das variáveis contínuas dependentes ${ }^{(1)}$ e independentes ${ }^{(2)}$ selecionadas para os modelos finais.

\begin{tabular}{lcccccccc}
\hline Variável & Número de lotes & Média & Desvio-padrão & Mínimo & Q1 $^{(3)}$ & Mediana & Q2 $^{(4)}$ & Máximo $^{2}$ \\
\hline PE (kg) & 690 & 22,5 & 2 & 16,5 & 21,2 & 22,5 & 23,9 & 27,6 \\
PS (kg) & 690 & 117 & 6 & 99 & 113 & 117 & 121 & 132 \\
DCT (dia) & 690 & 105 & 4 & 94 & 102 & 105 & 107 \\
CDR (kg por suíno) & 690 & 2,18 & 0,11 & 1,84 & 2,10 & 2,18 & 2,26 \\
CA (kg kg $\left.{ }^{-1}\right)$ & 690 & 2,44 & 0,13 & 2,21 & 2,34 & 2,41 & 2,50 & 2,53 \\
\hline
\end{tabular}

${ }^{(1)} \mathrm{CDR}$, consumo diário de ração; e CA, conversão alimentar. ${ }^{(2)} \mathrm{PE}$, peso de entrada; PS, peso de saída; e DCT, duração da fase de crescimento e terminação. ${ }^{(3)} \mathrm{Q} 1$, primeiro quartil. ${ }^{(4)} \mathrm{Q} 2$, segundo quartil. 
Spearman, para evitar multicolinearidade entre as variáveis contínuas e problemas de confusão entre as categóricas. Quando duas variáveis apresentaram coeficiente de correlação alto (valor absoluto $\geq 0,60$ ), apenas uma foi usada na análise multivariada, escolhida por seu valor de $\mathrm{p}$ nesta análise e por sua relevância biológica em relação à variável dependente. Posteriormente, todas as variáveis independentes selecionadas na análise de regressão simples foram submetidas ao procedimento "stepwise", tendo-se

Tabela 2. Variáveis categóricas independentes (fatores de produção), número e frequência de lotes ${ }^{(1)}$ em cada categoria dentro da cooperativa.

\begin{tabular}{|c|c|c|c|c|c|}
\hline Variável & Categoria & $\begin{array}{c}\text { NO e frequência } \\
(\%)^{(2)}\end{array}$ & Variável & Categoria & $\begin{array}{c}\text { NO e fre- } \\
\text { quência }(\%)^{(2)}\end{array}$ \\
\hline \multirow[t]{2}{*}{ Número de suínos por baia ${ }^{(3)}$} & $<20$ & $649(94,06)$ & Erisipela $^{(3)}$ & Sim & $7(100)$ \\
\hline & $20-40$ & $41(5,94)$ & Pasteurella $^{(3)}$ & Sim & $686(100)$ \\
\hline \multirow[t]{3}{*}{ Origem da água ${ }^{(3)}$} & Poço & $370(98,14)$ & Número de galpões ${ }^{(4)}$ & Um & $573(83,28)$ \\
\hline & Mina & $6(1,59)$ & & Dois ou mais & $115(16,72)$ \\
\hline & Rio & $1(0,27)$ & Tempo de construção ${ }^{(4)}$ & $<5$ anos & $309(44,78)$ \\
\hline \multirow[t]{3}{*}{ Material da tubulação(3) } & Mangueira & $53(7,73)$ & & $>5$ anos & $381(55,22)$ \\
\hline & Tubo PVC & $115(16,76)$ & Reforma das instalações ${ }^{(4)}$ & Sim & $125(19,03)$ \\
\hline & Misto & $518(75,51)$ & & Não & $532(80,97)$ \\
\hline Material do telhado ${ }^{(3)}$ & Argila & $676(100)$ & Material de separação das baias ${ }^{(4)}$ & $\begin{array}{l}\text { Misto (madeira e } \\
\text { alvenaria) }\end{array}$ & $73(10,8)$ \\
\hline Material do piso ${ }^{(3)}$ & Concreto & $690(100)$ & & Alvenaria & $603(89,2)$ \\
\hline \multirow[t]{2}{*}{ Lâmina d'água nas baias ${ }^{(3)}$} & Sim & $622(91,47)$ & Ventiladores $^{(4)}$ & Sim & $87(12,61)$ \\
\hline & Não & $58(8,53)$ & & Não & $603(87,39)$ \\
\hline \multirow[t]{2}{*}{ Caixa de retenção de dejetos ${ }^{(3)}$} & Sim & $616(91,94)$ & Posição da granja em relação ao sol ${ }^{(4)}$ & Diagonal & $441(65,24)$ \\
\hline & Não & $54(8,06)$ & & Contrário/paralela & $235(34,76)$ \\
\hline Luz elétrica $^{(3)}$ & Sim & $686(100)$ & Mão de obra ${ }^{(4)}$ & Não familiar & $181(26,66)$ \\
\hline Esterqueira $^{(3)}$ & Sim & $690(100)$ & & Familiar & $498(73,34)$ \\
\hline Exaustores $^{(3)}$ & Não & $690(100)$ & Árvores nas laterais dos galpões ${ }^{(5)}$ & Sim & $451(65,36)$ \\
\hline \multirow[t]{2}{*}{ Umidificadores/nebulizadores $^{(3)}$} & Sim & $46(6,67)$ & & Não & $239(34,64)$ \\
\hline & Não & $644(93,33)$ & Trimestre de entrada ${ }^{(5)}$ & Verão/outono & $341(49,42)$ \\
\hline \multirow[t]{2}{*}{ Agricultura próxima à granja ${ }^{(3)}$} & Sim & $547(80,44)$ & & Inverno/primavera & $349(50,58)$ \\
\hline & Não & $133(19,56)$ & Número de suínos alojados ${ }^{(6)}$ & $<500$ & $242(35,33)$ \\
\hline Número de rações ${ }^{(3)}$ & 4 & $690(100)$ & & $>500$ & $443(64,67)$ \\
\hline Rações diferenciadas por sexo(3) & Não & $690(100)$ & Tipo de comedouro $^{(6)}$ & Basculante & $88(13,15)$ \\
\hline Forma da ração $^{(3)}$ & Pellet & $690(100)$ & & $\begin{array}{l}\text { Semiautomático } \\
\text { cônico }\end{array}$ & $581(86,85)$ \\
\hline Choque de antibióticos ${ }^{(3)}$ & Sim & $87(100)$ & Tipo de bebedouro $^{(6)}$ & Chupeta & $591(85,51)$ \\
\hline Via de uso de antibióticos ${ }^{(3)}$ & Ração & $675(100)$ & & $\begin{array}{l}\text { Outros (taça ou } \\
\text { misto) }\end{array}$ & $100(14,49)$ \\
\hline Programas utilizados ${ }^{(3)}$ & $\begin{array}{l}\text { Ractopamina/ } \\
\text { imunocastração }\end{array}$ & $690(100)$ & $\operatorname{Sexo}^{(6)}$ & Machos castrados & $198(28,7)$ \\
\hline Número de genéticas ${ }^{(3)}$ & 2 & $690(100)$ & & Fêmeas & $175(25,36)$ \\
\hline Raças utilizadas $^{(3)}$ & $\begin{array}{c}\text { Large White/ } \\
\text { Landrace/Pietrain }\end{array}$ & $690(100)$ & & Misto & $317(45,94)$ \\
\hline Lotes sexados $^{(3)}$ & Sim & $690(100)$ & Material de construção dos galpões ${ }^{(7)}$ & Alvenaria & $617(89,42)$ \\
\hline Separação dos sexos nas baias ${ }^{(3)}$ & Não & $690(100)$ & & $\begin{array}{c}\text { Outros (madeira ou } \\
\text { misto) }\end{array}$ & $73(10,58)$ \\
\hline Ileíte $^{(3)}$ & Sim & $690(100)$ & Composteira $^{(7)}$ & Sim & $608(88,76)$ \\
\hline Pneumonia enzoótica ${ }^{(3)}$ & Sim & $690(100)$ & & Não & $77(11,24)$ \\
\hline Doença de Glasser ${ }^{(3)}$ & Sim & $690(100)$ & Origem dos animais $^{(7)}$ & $\mathrm{UPLs}^{(8)}$ & $469(67,97)$ \\
\hline Meningite $^{(3)}$ & Sim & $690(100)$ & & Multiplicadores & $221(32,03)$ \\
\hline
\end{tabular}

(1)Para algumas variáveis, o número de lotes que tiveram seus dados submetidos à análise de frequência foi menor que o total de lotes analisados (690). ${ }^{(2)} \mathrm{NO}$, número de observações e frequência entre parênteses. ${ }^{(3)}$ Variáveis inicialmente rejeitadas para as análises estatísticas devido à baixa variabilidade entre categorias. ${ }^{(4)}$ Variáveis inicialmente consideradas para as análises estatísticas. ${ }^{(5)}$ Variáveis incluídas nos dois modelos finais, para consumo diário de ração (CDR) e conversão alimentar (CA). ${ }^{(6)}$ Variáveis incluídas somente no modelo final para CDR. ${ }^{(7)}$ Variáveis incluídas somente no modelo final para CA. ${ }^{(8)}$ UPLs, unidades produtoras de leitões. 
mantido, no modelo multivariado final, todos os fatores que apresentaram $p<0,05$. Como havia variáveis com número de lotes menor que o total de lotes analisados, também foi realizada a seleção manual das variáveis independentes, com o intuito de observar se as variáveis selecionadas pelo procedimento "stepwise" eram iguais àquelas selecionadas pelo procedimento manual; no entanto, ambos os procedimentos selecionaram as mesmas variáveis.

Testes para a avaliação dos efeitos fixos foram baseados no teste $\mathrm{F}$, em que os graus de liberdade do denominador eram aproximados pelo procedimento Satterthwaite. Interações significativas $(p<0,05)$ entre as variáveis no modelo multivariado foram testadas e incluídas. Após a obtenção dos modelos para cada variável dependente, os resíduos foram plotados contra os valores previstos para verificar a homogeneidade das variâncias e a presença de "outliers". Os fatores que apresentaram $\mathrm{p}<0,05$ no modelo final foram considerados estatisticamente significantes para uma dada variável dependente.

\section{Resultados e Discussão}

$\mathrm{Na}$ análise de regressão linear múltipla, as variáveis mantidas no modelo final que influenciaram significativamente o CDR foram: árvores nas laterais dos galpões ( $p<0,01)$, sexo dos animais $(p<0,001)$, peso de entrada (PE, $\mathrm{p}<0,001)$ e peso de saída (PS, $\mathrm{p}<0,001)$ (Tabela 3).

Nos lotes de animais mantidos em granjas com árvores nas laterais dos galpões, o CDR diminuiu em comparação ao nos lotes de animais alojados em granjas sem árvores nas laterais (Tabela 3). Este resultado difere dos de outros trabalhos, uma vez que o CDR foi menor nas granjas arborizadas que, em tese, seriam um ambiente mais favorável ao consumo do que as não arborizadas.

Segundo Miller (2012), o desempenho é maximizado quando os animais são mantidos dentro de sua zona termoneutra. Embora não tenham sido encontrados trabalhos que relacionassem diretamente $o$ fator “árvores nas laterais dos galpões" com os parâmetros de desempenho do animal, observou-se que o plantio de árvores paralelas às instalações diminuiu a incidência direta do sol sobre os animais e produziu uma área com temperatura mais amena (Dias et al.,
2011), o que favoreceu o conforto térmico dos suínos em dias quentes.

Já a relação negativa entre o aumento da temperatura e o consumo de ração pelos suínos foi mostrada em vários estudos com animais em fase de crescimento, que apontaram redução de 15,12 e $14,3 \%$ no consumo de ração quando os animais foram mantidos sob estresse por calor, em comparação aos mantidos em temperaturas amenas (Le Bellego et al., 2002; Manno et al., 2006; Kiefer et al., 2009).

Assim, ao se considerar que as árvores nas laterais dos galpões proporcionam um clima mais favorável ao consumo de ração do que os ambientes onde os suínos sofrem estresse por calor, os resultados do presente trabalho vão contra os anteriores. Entretanto, devese destacar que o uso deste recurso para melhorar a qualidade ambiental da granja pode refletir a grande atenção dos produtores à granja como um todo, o que inclui um manejo mais adequado de arraçoamento ou de outros fatores não detectados, que culminaram na redução do consumo. Esta hipótese pode ser efetivamente verdadeira já que, nas granjas com arborização nas laterais dos barracões, houve melhora da CA (Tabela 4).

Com relação à variável sexo, lotes compostos apenas por fêmeas tiveram CDR menor do que os lotes mistos (machos castrados e fêmeas) (Tabela 3). De forma similar, Morales et al. (2011) constataram um CDR 6,1\% maior para machos castrados do que para fêmeas, também em fase de CT. Esses resultados podem ser atribuídos ao fato de os machos castrados consumirem mais alimento e crescerem mais rapidamente do que as fêmeas (Brustolini \& Fontes, 2014).

Quanto às variáveis $\mathrm{PE}$ e PS dos lotes, observou-se que, à medida que ambos os pesos aumentam, o CDR também aumenta (Tabela 3), uma vez que animais mais pesados consomem mais ração, o que corrobora os resultados obtidos por Pierozan et al. (2016).

No modelo para CA, todas as variáveis selecionadas para o modelo final interferiram significativamente nesse parâmetro, a saber: trimestre de entrada $(\mathrm{p}<0,001)$, material de construção dos galpões $(\mathrm{p}=0,04)$, composteira $(\mathrm{p}=0,001)$, árvores nas laterais dos galpões $(p=0,01)$, origem dos animais $(p<0,001)$, PE $(p<0,001)$ e DCT $(p<0,001)$ (Tabela 4).

A CA foi melhor nos lotes de animais alojados no período de verão/outono, quando comparados aos no inverno/primavera (Tabela 4). Porém, os estudos 
sobre a influência da temperatura na CA apresentam resultados divergentes. Le Bellego et al. (2002) não encontraram efeitos da temperatura $\left(22\right.$ versus $\left.29^{\circ} \mathrm{C}\right)$ sobre a CA de suínos, tanto na fase de crescimento quanto na de terminação; contudo, Kiefer et al. (2009), em trabalho com suínos entre 30 e $60 \mathrm{~kg}$ de peso vivo, relataram piora na $\mathrm{CA}$ para animais mantidos sob calor do que em ambiente termoneutro. Já Manno et al. (2006) obtiveram melhores valores de CA para os animais mantidos sob altas temperaturas $\left(32^{\circ} \mathrm{C}\right)$ do que em conforto térmico $\left(22^{\circ} \mathrm{C}\right)$. Esses resultados contrastantes podem estar relacionados aos níveis de desempenho, ao genótipo dos animais utilizados ou à resposta marginal do ganho de peso decorrente de uma mudança na alimentação (Le Bellego et al., 2002).

Com relação à variável material de construção dos galpões, animais mantidos em granjas de alvenaria apresentaram melhor CA do que os mantidos em granjas de madeira ou granjas mistas feitas de madeira e alvenaria (Tabela 4). A escolha do material em ambientes agrícolas afeta a condição de higiene das superfícies (Määttä et al., 2008), e a facilidade de limpeza é uma característica importante relacionada à higiene dos pavimentos, fator que afeta a saúde dos suínos (Kymäläinen et al., 2008). Muitas vezes, a madeira sofre degradação por alguns fatores que podem reduzir a vida útil da estrutura, com destaque para umidade, exposição à luz solar direta e mudanças climáticas repentinas (Mariño et al., 2009). Além disso, a mais rápida degradação das estruturas de madeira em relação às de concreto talvez dificulte uma boa limpeza e desinfecção. Isso poderia proporcionar um status sanitário superior para os animais provenientes de granjas de alvenaria, o que favoreceria a melhora de parâmetros de desempenho, que incluem a $\mathrm{CA}$, como observado no presente trabalho.

Animais mantidos em granjas onde o recurso da compostagem era utilizado para o tratamento de animais mortos apresentaram melhor $\mathrm{CA}$ do que os animais em granjas sem composteiras (Tabela 4). A compostagem é um processo amplamente aeróbico em que bactérias, fungos e outros microrganismos convertem matéria orgânica em húmus estável (Berge et al., 2009). Nesse processo, a temperatura é considerada como elemento principal na inativação de patógenos (Wilkinson, 2007).

Quando realizada de forma correta, a compostagem como destino de animais que morrem na granja favorece a sanidade dos rebanhos e pode influenciar o desempenho dos animais, como foi observado com a variável CA no presente trabalho. Nas unidades de produção de suínos sem composteira, a eliminação das carcaças pode ocorrer de forma inadequada, o que compromete a biosseguridade e/ou a sanidade das explorações e, consequentemente, reflete na produtividade. Também é possível inferir

Tabela 3. Modelo de regressão linear múltipla (modelo final) para estimativa dos efeitos dos fatores de produção sobre o consumo diário de ração (CDR) (em quilograma por suíno) em 690 lotes de 118 granjas de crescimento e terminação de suínos.

\begin{tabular}{|c|c|c|c|c|c|c|}
\hline \multirow[t]{2}{*}{ Variável } & \multirow[t]{2}{*}{ Categoria } & \multirow[t]{2}{*}{ Média (kg) } & \multirow{2}{*}{$\begin{array}{c}\text { Estimativa } \\
\text { (erro-padrão) }\end{array}$} & \multicolumn{3}{|c|}{ Intervalo de confiança de $95 \%$} \\
\hline & & & & Inferior & Superior & Valor de $\mathrm{p}$ \\
\hline Intercepto & - & - & $0,43(0,06)$ & 0,31 & 0,55 & $<0,001$ \\
\hline \multirow{2}{*}{ Árvores nas laterais dos galpões } & Sim & 2,18 & $-0,03(0,01)$ & $-0,05$ & $-0,01$ & $<0,01$ \\
\hline & Não & 2,21 & 0 & - & - & - \\
\hline \multirow{2}{*}{$\begin{array}{l}\text { Trimestre de } \\
\text { entrada }\end{array}$} & Verão/outono & 2,20 & $0,008(0,005)$ & $-0,002$ & 0,017 & 0,12 \\
\hline & Inverno/primavera & 2,19 & 0 & - & - & - \\
\hline \multirow{3}{*}{$\begin{array}{l}\mathrm{NSA}^{(1)} / \text { tipo de } \\
\text { comedouro }\end{array}$} & $<500 /$ basculante & 2,17 & $-0,02(0,02)$ & $-0,07$ & $-0,02$ & 0,29 \\
\hline & $<500 /$ S.C. ${ }^{(2)}$ & 2,21 & $0,02(0,01)$ & $-0,01$ & 0,04 & 0,25 \\
\hline & $>500 /$ S.C. ${ }^{(2)}$ & 2,20 & 0 & - & - & - \\
\hline \multirow{2}{*}{ Tipo de bebedouro } & Chupeta & 2,18 & $-0,04(0,02)$ & $-0,08$ & 0,008 & 0,11 \\
\hline & Outros $^{(3)}$ & 2,21 & 0 & - & - & - \\
\hline \multirow{3}{*}{ Sexo } & Machos castrados & 2,20 & $-0,005(0,006)$ & $-0,02$ & 0,007 & 0,41 \\
\hline & Fêmeas & 2,17 & $-0,035(0,006)$ & $-0,05$ & $-0,02$ & $<0,001$ \\
\hline & Misto & 2,21 & 0 & - & - & - \\
\hline Peso de entrada (PE, kg) & - & - & $0,008(0,001)$ & 0,005 & 0,01 & $<0,001$ \\
\hline Peso de saída (PS, kg) & - & - & $0,01(0,00)$ & 0,01 & 0,02 & $<0,001$ \\
\hline
\end{tabular}

${ }^{(1)}$ NSA, número de suínos alojados. ${ }^{(2)}$ S.C., semiautomático cônico. ${ }^{(3)}$ Taça ou misto. 
que produtores que prezam por esse recurso na propriedade comumente também são atentos a outros fatores ou processos que promovem a qualidade sanitária do rebanho, o que sinaliza para melhores resultados de CA.

Outro fator que interferiu de forma significativa na $\mathrm{CA}$ e que também pode estar relacionado ao status sanitário do rebanho foi a origem dos animais. Lotes de suínos provenientes de unidades produtoras de leitões (UPLs), alojados nas unidades de CT, apresentaram melhor $\mathrm{CA}$ do que os originários de granjas multiplicadoras (Tabela 4); estes resultados são semelhantes aos observados por Silva et al. (2015), em estudo com 1.533 lotes de suínos em fase de CT. Oliveira et al. (2007) e Agostini et al. (2014) verificaram que, uma vez que as unidades de ciclo completo são menores que as UPLs, são necessários animais de mais de uma granja de ciclo completo para completar os lotes das granjas de CT, o que pode aumentar os riscos de introdução de doenças. Além disso, não é incomum que estas granjas estejam menos sujeitas aos rigores sanitários e se localizem próximas a outras granjas, o que facilita a transmissão de agentes infecciosos (Pierozan et al., 2016).

Quanto às variáveis PE e duração da engorda, foi identificada relação de piora do índice com o aumento do peso inicial e com o maior período de engorda. Esta relação está baseada na piora da eficiência alimentar em animais de maior peso. A CA é piorada quando os animais entram mais pesados e/ou permanecem mais tempo na granja. Esses resultados estão de acordo com os obtidos por Agostini et al. (2014) e Pierozan et al. (2016).

Os valores de variância para o modelo nulo e para o modelo final do CDR e da CA estão descritos na Tabela 5. A diferença da variância total entre o modelo nulo e o final indicou que cerca de 61 e $63 \%$ da variância total foi explicada pelas variáveis incluídas no modelo final para CDR e CA, respectivamente. Para CDR e CA, respectivamente, foi observada variabilidade explicada de 61,9 e 24,8\%, por Agostini et al. (2014), e de 50 e $64 \%$ por Pierozan et al. (2016). Já Oliveira et al. (2009) verificaram aproximadamente $80,8 \%$ de variância para consumo total de ração por suíno. Vale ressaltar que a comparação da percentagem de variância explicada entre os diferentes estudos se torna subjetiva devido às diferenças de variabilidade ou aos distintos fatores estudados (Agostini et al., 2014).

$\mathrm{Na}$ Espanha, é comum a alta homogeneidade entre granjas de uma mesma empresa (Agostini et al., 2015), o que também ocorre em algumas regiões do Brasil, nas quais as cooperativas são altamente integradas, com características de instalações, manejo, nutrição e saúde do rebanho muito semelhantes ou até iguais entre si, como é o caso da cooperativa avaliada no presente trabalho. Apesar de muitas das variáveis estudadas apresentarem pouca variabilidade, foi possível identificar, por meio dos modelos de regressão

Tabela 4. Modelo de regressão linear múltipla (modelo final) para estimativa dos efeitos dos fatores de produção sobre a conversão alimentar (CA) (em quilograma de ração por quilograma de suíno) em 690 lotes de 118 granjas de crescimento e terminação de suínos.

\begin{tabular}{|c|c|c|c|c|c|c|}
\hline \multirow[t]{2}{*}{ Variável } & \multirow[t]{2}{*}{ Categoria } & \multirow{2}{*}{$\begin{array}{c}\text { Média } \\
\left(\mathrm{kg} \mathrm{kg}^{-1}\right)\end{array}$} & \multirow{2}{*}{$\begin{array}{c}\text { Estimativa } \\
\text { (erro-padrão) }\end{array}$} & \multicolumn{3}{|c|}{ Intervalo de confiança de 95\% } \\
\hline & & & & Inferior & Superior & Valor de $\mathrm{p}$ \\
\hline Intercepto & - & - & $1,35(0,09)$ & 1,16 & 1,54 & $<0,001$ \\
\hline \multirow{2}{*}{ Árvores nas laterais dos galpões } & Sim & 2,49 & $-0,03(0,01)$ & $-0,05$ & $-0,006$ & 0,01 \\
\hline & Não & 2,52 & 0 & - & - & - \\
\hline \multirow{2}{*}{$\begin{array}{l}\text { Trimestre de } \\
\text { entrada }\end{array}$} & Verão/outono & 2,49 & $-0,03(0,01)$ & $-0,04$ & $-0,02$ & $<0,001$ \\
\hline & Inverno/primavera & 2,51 & 0 & - & - & - \\
\hline \multirow{2}{*}{ Material de construção dos galpões } & Alvenaria & 2,48 & $-0,04(0,02)$ & $-0,08$ & $-0,002$ & 0,04 \\
\hline & Outros $^{(1)}$ & 2,52 & 0 & - & - & - \\
\hline \multirow{2}{*}{ Composteira } & Sim & 2,47 & $-0,07(0,02)$ & $-0,10$ & $-0,03$ & $<0,001$ \\
\hline & Não & 2,53 & 0 & - & - & - \\
\hline \multirow{2}{*}{ Origem dos animais } & $\mathrm{UPLs}^{(2)}$ & 2,45 & $-0,11(0,008)$ & $-0,12$ & $-0,09$ & $<0,001$ \\
\hline & Multiplicadores & 2,56 & 0 & - & - & - \\
\hline Peso de entrada $(\mathrm{kg})$ & - & - & $0,016(0,002)$ & 0,01 & 0,02 & $<0,001$ \\
\hline$\underline{\mathrm{DCT}^{(3)}(\mathrm{dia})}$ & - & - & $0,009(0,001)$ & 0,007 & 0,01 & $<0,001$ \\
\hline
\end{tabular}

${ }^{(1)}$ Madeira ou misto. ${ }^{(2)}$ UPLs, unidades produtoras de leitões. ${ }^{(3)}$ DCT, duração da fase de crescimento e terminação. 
Tabela 5. Variância estimada entre granjas e entre lotes dentro de uma granja para os modelos nulo (sem preditores) e final (com preditores), bem como percentagem de variância explicada pelas variáveis incluídas nos modelos finais para consumo diário de ração (CDR) e conversão alimentar (CA).

\begin{tabular}{|c|c|c|c|c|c|c|}
\hline \multirow[t]{3}{*}{ Efeito } & \multicolumn{4}{|c|}{ Variância estimada } & \multirow{2}{*}{\multicolumn{2}{|c|}{$\begin{array}{c}\text { Variância } \\
\text { explicada (\%) }\end{array}$}} \\
\hline & \multicolumn{2}{|c|}{ Modelo nulo } & \multicolumn{2}{|c|}{ Modelo final } & & \\
\hline & CDR & $\mathrm{CA}$ & $\mathrm{CDR}$ & $\mathrm{CA}$ & $\mathrm{CDR}$ & $\mathrm{CA}$ \\
\hline Granja & $0,00258(19,7 \%)$ & $0,00885(49,1 \%)$ & $0,00163(32,0 \%)$ & $0,00245(36,7 \%)$ & 36,8 & 72,3 \\
\hline Lotes dentro da granja & $0,01051(80,3 \%)$ & $0,00917(50,9 \%)$ & $0,00346(68,0 \%)$ & $0,00423(63,3 \%)$ & 67,1 & 53,9 \\
\hline Total & $0,01309(100 \%)$ & $0,01802(100 \%)$ & $0,00509(100 \%)$ & $0,00668(100 \%)$ & 61,1 & 62,9 \\
\hline
\end{tabular}

linear múltipla, alguns dos fatores que efetivamente agem sobre o CDR e a CA nas granjas de CT.

\section{Conclusões}

1. Sob condições reais de campo, os fatores árvores nas laterais dos galpões e sexo do animal agem sobre o consumo diário de ração (CDR), e os fatores árvores nas laterais dos galpões, material de construção dos galpões, composteira e origem dos animais agem sobre a conversão alimentar (CA) de suínos em crescimento e terminação (CT).

2. Os modelos de regressão linear múltipla possibilitam identificar variáveis de importância e estimar seus efeitos sobre a CA e o CDR de suínos nas fases de CT dentro de um sistema cooperativo.

\section{Agradecimentos}

À Cooperativa Agroindustrial Consolata (Copacol), pela disponibilização dos dados e pela abertura das granjas; e ao Ministerio de Educación, Cultura y Deporte (AGL 2011-29960), pelo apoio financeiro.

\section{Referências}

AGOSTINI, P. da S.; MANZANILlA, E.G.; BLAS, C. de; FAHEY, A.G.; SILVA, C.A. da; GASA, J. Managing variability in decision making in swine growing-finishing units. Irish Veterinary Journal, v.68, p.1-13, 2015. DOI: 10.1186/ s13620-015-0048-z.

AGOSTINI, P.S.; FAHEY, A.G.; MANZANILLA, E.G.; O'DOHERTY, J.V.; BLAS, C. de; GASA, J. Management factors affecting mortality, feed intake and feed conversion ratio of grow-finishing pigs. Animal, v.8, p.1312-1318, 2014. DOI: 10.1017/ S1751731113001912.

AGOSTINI, P.S.; GASA, J.; MANZANILLA, E.G.; SILVA, C.A. da; de BLAS, C. Descriptive study of production factors affecting performance traits in growing-finishing pigs in Spain. Spanish
Journal of Agricultural Research, v.11, p.371-381, 2013. DOI: 10.5424/sjar/2013112-3011.

BERGE, A.C.B.; GRANVILLE, T.D.; MILLNER, P.D.; KLINGBORG, D.J. Methods and microbial risks associated with composting of animal carcasses in the United States. Journal of the American Veterinary Medical Association, v.234, p.47-56, 2009. DOI: $10.2460 /$ javma.234.1.47.

BRUSTOLINI, A.P.L.; FONTES, D. de O. Fatores que afetam a exigência nutricional de suínos na terminação. In: FERREIRA, A.D.; CARRARO, B.; DALLANORA, D.; MACHADO, D.; MACHADO, I.P.; PINHEIRO, R.; ROHR, S. (Coord.). Produção de suínos: teoria e prática. Brasília: ABCS, 2014. cap.16, p.677-685.

CAVIGLIONE, J.H.; KIIHL, L.R.B.; CARAMORI, P.H.; OLIVEIRA, D. Cartas climáticas do Paraná. Londrina: IAPAR, 2000. Disponível em: <http://www.iapar.br/modules/conteudo/ conteudo.php?conteudo=677 $>$. Acesso em: 12 jun. 2016 .

DIAS, A.C.; CARRARO, B.Z.; DALLANORA, D.; COSER, F.J.; MACHADO, G.S.; MACHADO, I.P.; PINHEIRO, R.; ROHR, S.A. Manual brasileiro de boas práticas agropecuárias na produção de suínos. Brasília: ABCS: MAPA; Concórdia: Embrapa Suínos e Aves, 2011. 140p.

DOUGLAS, S.L.; SZYSZKA, O.; STODDART, K.; EDWARDS, S.A.; KYRIAZAKIS, I. Animal and management factors influencing grower and finisher pig performance and efficiency in European systems: a meta-analysis. Animal, v.9, p.1210-1220, 2015. DOI: $10.1017 /$ S1751731115000269.

HECK, A. Fatores que influenciam o desenvolvimento dos leitões na recria e terminação. Acta Scientiae Veterinariae, v.37, p.s211-s218, 2009. Supplement 1.

HOYT, W.T.; LEIERER, S.; MILLINGTON, M.J. Analysis and interpretation of findings using multiple regression techniques. Rehabilitation Counseling Bulletin, v.49, p.223-233, 2006. DOI: 10.1177/00343552060490040401.

KIEFER, C.; MEIGNEN, B.C.G.; SANCHES, J.F.; CARRIJO, A.S. Resposta de suínos em crescimento mantidos em diferentes temperaturas. Archivos de Zootecnia, v.58, p.55-64, 2009. DOI: 10.4321/S0004-05922009000100006.

KYMÄLÄINEN, H.R.; MÄÄTTÄ, J.; PUUMALA, M.; KAUSTELL, K.O.; MATTILA, T.; JOUTSEN, B.-L.; KUISMA, R.; HURME, K.-R.; UUSI-RAUVA, A.; SJÖBERG, A.-M. A laboratory study of the effect of coating 
on cleanability of concrete flooring for use in piggeries. Biosystems Engineering, v.99, p.88-98, 2008. DOI: 10.1016/j. biosystemseng.2007.09.002.

LE BELLEGO, L.; van MILGEN, J.; NOBLET, J. Effect of high temperature and low-protein diets on the performance of growing-finishing pigs. Journal of Animal Science, v.80, p.691-701, 2002. DOI: 10.2527/2002.803691x.

MÄÄTTÄ, J.; KYMÄLÄINEM, H.-R.; HELLSTEDT, M.; MAHLBERG, R.; KUISMA, R.; SALPARANTA, L.; LÖIJA, M.; TALIBACHEW, A.; HURME, K.-R.; UUSI-RAUVA, A.; RITSCHKOFF, A.-C.; SJÖBERG, A.-M. Properties and cleanability of new and traditional agricultural surface materials. Agricultural and Food Science, v.17, p.210-226, 2008. DOI: $10.2137 / 145960608786118776$.

MAES, D.G.D.; DUCHATEAU, L.; LARRIESTRA, A.; DEEN, J.; MORRISON, R.B.; de KRUIF, A. Risk factors for mortality in grow-finishing pigs in Belgium. Journal of Veterinary Medicine. B, Infectious Diseases and Veterinary Public Health, v.51, p.321-326, 2004. DOI: 10.1111/j.1439-0450.2004.00780.x.

MANNO, M.C.; OLIVEIRA, R.F.M. de; DONZELE, J.L.; OLIVEIRA, W.P. de; VAZ, R.G.M.V.; SILVA, B.A.N.; SARAIVA, E.P.; LIMA, K.R. de S. Efeitos da temperatura ambiente sobre o desempenho de suínos dos 30 aos $60 \mathrm{~kg}$. Revista Brasileira de Zootecnia, v.35, p.471-477, 2006. DOI: 10.1590/ S1516-35982006000200019.

MARIÑO, R.A.; CARREIRA, X.C.; FERNÁNDEZ, M.E.; FERNANDEZ-RODRIGUES, C. Durability of timber structures in agricultural and livestock buildings. Biosystems Engineering, v.104, p.152-160, 2009. DOI: 10.1016/j. biosystemseng.2009.06.009.

MILLER, T.G. Swine feed efficiency: influence of temperature. Iowa: Iowa Pork Industry Center Fact Sheets, 2012. 2p. Paper 11. Disponível em: <http://www.swinefeedefficiency.com/factsheets/ IPIC25f\%20SFE\%20Influence\%20of\%20Temperature.pdf>. Acesso em: 20 nov. 2015.

MORALES, J.I.; CÁMARA, L.; BERROCOSO, J.D.; LÓPEZ, J.P.; MATEOS, G.G.; SERRANO, M.P. Influence of sex and castration on growth performance and carcass quality of crossbred pigs from 2 Large White sire lines. Journal of Animal Science, v.89, p.3481-3489, 2011. DOI: 10.2527/jas.2010-3357.
NEALE, M.C.; EAVES, L.J.; HEATH, A.C.; KESSLER, R.C.; KENDLER, K.S. Multiple regression with data collected from relatives: testing assumptions of the model. Multivariate Behavioral Research, v.29, p.33-61, 1994. DOI: 10.1207/ s15327906mbr2901_2.

NOLLET, N.; MAES, D.; DE ZUTTER, L.; DUCHATEAU, L.; HOUF, K.; HUYSMANS, K.; IMBERECHTS, H.; GEERS, R.; de KRUIF, A.; VAN HOOF, J. Risk factors for the herd-level bacteriologic prevalence of Salmonella in Belgian slaughter pigs. Preventive Veterinary Medicine, v.65, p.63-75, 2004. DOI: 10.1016/j.prevetmed.2004.06.009.

OLIVEIRA, J.; GUITIÁN, F.J.; YUS, E. Effect of introducing piglets from farrow-to-finish breeding farms into all-in all-out fattening batches in Spain on productive parameters and economic profit. Preventive Veterinary Medicine, v.80, p.243-256, 2007. DOI: 10.1016/j.prevetmed.2007.02.003.

OLIVEIRA, J.; YUS, E.; GUITIÁN, F.J. Effects of management, environmental and temporal factors on mortality and feed consumption in integrated swine fattening farms. Livestock Science, v.123, p.221-229, 2009. DOI: 10.1016/j.livsci.2008.11.016.

PIEROZAN, C.R.; AGOSTINI, P.S.; GASA, J.; NOVAIS, A.K; DIAS, C.P.; SANTOS, R.S.K.; PEREIRA JR., M.; NAGI, J.G.; ALVES, J.B.; SILVA, C.A. Factors affecting the daily feed intake and feed conversion ratio of pigs in grow-finishing units: the case of a company. Porcine Health Management, v.2, p.1-8, 2016. DOI: 10.1186/s40813-016-0023-4.

SILVA, C.A.; AGOSTINI, P. da S.; GASA, J. Uso de modelos matemáticos para analisar a influência de fatores de produção sobre a mortalidade e desempenho de suínos de terminação. In: BARCELlOS, D.E.; BORTOLOZZO, F.P.; WENTZ, I.; BERNARDI, M.L. (Ed.). Avanços em sanidade, produção e reprodução de suínos. Porto Alegre: Universidade Federal do Rio Grande do Sul, Setor de Suínos, 2015. p.267-284.

TUOVINEN, V.K.; GRÖHN, Y.T.; STRAW, B.E.; BOYD, R.D. Feeder unit environmental factors associated with partial carcass condemnations in market swine. Preventive Veterinary Medicine, v.12, p.175-195, 1992. DOI: 10.1016/0167-5877(92)90048-K.

WILKINSON, K.G. The biosecurity of on-farm mortality composting. Journal of Applied Microbiology, v.102, p.609-618, 2007. DOI: 10.1111/j.1365-2672.2006.03274.x.

Recebido em 8 de abril de 2016 e aprovado em 27 de junho de 2016 